\title{
Cancer and other causes of death among a cohort of dry cleaners
}

\author{
A Blair, Patricia A Stewart, P E Tolbert, D Grauman, F X Moran, J Vaught, Judith Rayner
}

\begin{abstract}
Mortality among 5365 members of a dry cleaning union in St Louis, Missouri, was less than expected for all causes combined $(S M R=0.9)$ but slightly raised for cancer $(S M R=1 \cdot 2)$. Among the cancers, statistically significant excesses occurred for oesophagus $(\mathrm{SMR}=\mathbf{2 \cdot 1})$ and cervix (SMR $=1 \cdot 7)$ and non-significant excesses for larynx $(S M R=1 \cdot 6)$, lung $($ SMR $=1 \cdot 3)$, bladder $($ SMR $=1 \cdot 7)$, thyroid (SMR = 3.3), lymphosarcoma and reticulosarcoma (SMR $=1 \cdot 7)$, and Hodgkin's disease (SMR = 2·1). Mortality from emphysema was also significantly raised $(S M R=2 \cdot 0)$. Eleven of the 13 deaths from oesophageal cancer occurred among black men. The risk of this cancer showed a significant association with estimated cumulative exposure to dry cleaning solvents (rising to $\mathbf{2 \cdot 8}$-fold in the highest category) but not with level or duration of exposure. Mortality from kidney cancer was not excessive as reported in other studies. Excesses for emphysema and cancers of the larynx, lung, oesophagus, bladder, and cervix may be related to socioeconomic status, tobacco, or alcohol use. Although the number of deaths was small, the greatest risk for cancers of the lymphatic and haematopoietic system (fourfold) occurred among workers likely to have held jobs where exposures were the heaviest. Small numbers and limited information on exposure to specific substances complicates interpretation of this association but is unlikely to be due to confounding by tobacco use. It was not possible to identify workers exposed to specific dry cleaning solvents but mortality among those entering the union after 1960, when use of perchloroethylene was predominant, was similar to those entering before 1960 .
\end{abstract}

Epidemiology and Biostatistics Program, National Cancer Institute, Rockville, MD 20892, USA A Blair, P A Stewart, D Grauman

University of North Carolina, Chapel Hill, NC

P E Tolbert

Westat,Inc, Rockville, MD

F X Moran, J Vaught, J Rayner
Over the years, the dry cleaning industry has used ${ }_{\sigma}$ several organic solvents including carbon tetra- $O$ chloride, Stoddard solvent, tetrachloroethylene (per- $\frac{\mathbb{}}{3}$ chloroethylene), trichloroethylene, and fluorocarbons. Stoddard solvent dominated the industry until i $\omega$ the 1930s when carbon tetrachloride became $\vec{A}$ popular. Both Stoddard solvent and carbon tetra- $N$ chloride were largely replaced in the 1960 s by $\frac{\text { ? }}{2}$ perchloroethylene which is now used by approxi- $\rightarrow$ mately $75 \%$ of the retail dry cleaners in the United States. ${ }^{1}$ Petroleum solvents, such as Stoddard solvent, remain the solvent of choice, however, for large industrial cleaning operations. Recently, $\vec{\bullet}$ fluorocarbons have become popular. A few other solvents such as turpentine, camphene, naphtha, and gasoline have occasionally been used, particularly during the second world war when supplies of specific chemicals were limited. Carbon tetrachloride perchloroethylene, and trichloroethylene $\stackrel{\square}{\perp}$ have caused cancer in animals. ${ }^{2}$

With about 133000 individuals employed in the about 20000 dry cleaning establishments in the United States, the number of workers exposed to suspected human carcinogens could be considerable. ${ }^{3} \mathrm{~A}$ few epidemiological studies of workers $\mathbb{\Phi}$ in the dry cleaning industry have been completed. Although the evidence is conflicting, these studies have suggested associations with leukaemia ${ }^{45}$ and cancers of the lung, ${ }^{46}$ cervix $^{47}$ colon, ${ }^{48}$ kidney, ${ }^{4-7}$ 웅 pancreas, ${ }^{49}$ bladder, ${ }^{578}$ and liver. ${ }^{41011}$ We followed up our preliminary proportionate mortality inves- $\frac{}{工}$ tigation ${ }^{4}$ with a cohort mortality study of workers $D$ who were members of a dry cleaning union in St Louis, Missouri, to evaluate the mortality experience $N$ of this larger population.

\section{Methods}

STUDY POPULATION

The cohort was assembled from historical dues records maintained by Local No 161 (St Louis) of the Laundry, Dry Cleaning, and Dye House Workers' International Union and includes some of the deaths $\frac{0}{0}$ covered in a previous report by the senior author. ${ }^{4} \frac{\vec{D}}{\mathbb{D}}$ Members of Local 161 worked exclusively in dry $\frac{?}{0}$ cleaning establishments. From dues records for each $\cong$ union member admitted before 1978, we abstracted $\bar{\sigma}$ name, social security number, date of birth, year and $\delta$ age of entry into the union, number of dues paying? 
months by calendar year, race, sex, job titles (usually from around the time of entry), and most recent firm where employed. When not available from dues records, race, sex, and date of birth were sought from other sources including driver's licence records, social security files, health care finance administration records, and credit bureaus. Race or sex, or both, could not be determined for 322 union members employed for one year or more.

Vital status of study subjects on 1 January 1979 (the closing date of the study) was determined using information from union records, social security administration, motor vehicle departments, credit bureaus, state bureaus of social services, and telephone and street directories. Death certificates were coded by an experienced nosologist. Underlying and contributing causes of death were determined using the International Classification of Diseases rules in effect at the time of death and were assigned rubrics according to the eighth revision.

\section{EXPOSURE ASSESSMENT}

It was not possible to identify exposure to specific chemicals because of the large number of dry cleaning establishments (many of which had gone out of business), the changing use of solvents over the past 30 years, and the lack of historical monitoring data in these establishments. Reports of monitoring in other dry cleaning shops indicated that exposure levels to perchloroethylene and other dry cleaning solvents (Stoddard solvent and fluorocarbons) tended to be remarkably consistent from shop to shop. ${ }^{12-16}$ Indices of exposure to dry cleaning were developed which approximate the reported measurements.

There are four major categories of jobs in the dry cleaning industry. The cleaners, who generally run the dry cleaning machines and transfer the wet clothes; the pressers and sewers who iron and repair the clothes; the counter workers who receive and dispense the clothing to the public; and other miscellaneous workers including maintenance workers (table 1). Monitoring data indicate that the cleaners probably have the highest eight hour time weighted

Table 1 Exposure indices based on job and type of establishment

\begin{tabular}{lrl}
\hline Rank & Index & Sample job titles \\
\hline & & Eight hour TW $A$ exposure \\
Zero & 0 & Counter at pickup station only \\
$\begin{array}{l}\text { Medium } \\
\text { High }\end{array}$ & 7 & Counter, presser, sewer, maintenance \\
& 40 & $\begin{array}{l}\text { Cleaner } \\
\text { Ceiling exposure }\end{array}$ \\
$\begin{array}{l}\text { Zero } \\
\text { Medium } \\
\text { High }\end{array}$ & 0 & Counter at pickup station only \\
\hline
\end{tabular}

average (TWA) owing to their proximity to the source (the washers), and that they also receive high, short term exposures during the transfer of the wet clothes. ${ }^{12-16}$ Cleaners were, therefore, assigned an exposure index of $\mathbf{4 0}$ for an eight hour TWA and 60 as an index for a ceiling exposure. Pressers, sewers, and counter workers, employed in shops where dry cleaning took place, are further from the washers than the cleaners and receive their exposures from the ambient air. Their highest ceiling exposure is likely to be similar to their eight hour TWA. Therefore, they were given an index of seven for both the TWA and the ceiling. Maintenance workers were likely to have received their eight hour exposures from the ambient air, but would get high, short term ceiling exposures when repairing the washers. They were assigned a TWA of 7 and a ceiling of 60 . For counter workers employed in pick up stations-that is, locations where no cleaning was done on the premises-an index of zero was assigned.

Several measures of exposure were used to evaluate the relation between mortality and exposure to dry cleaning solvents. Duration of union membership was used as a surrogate for duration of exposure. This measure was an imperfect measure of duration because it would underestimate work months when workers were delinquent in paying dues, or when they worked for non-union shops. On the other hand, members not employed in dry cleaning may have continued to pay dues in order to remain in the union health benefit plan, a situation where duration of membership would overestimate duration of exposure.

The estimated indices of solvent exposure were used to evaluate mortality by level, peak, and cumulative exposure. A cumulative exposure scale was developed by multiplying the exposure index for the job title (usually at entry to the union) by the number of months of union membership. For 978 subjects, however, a second job title was also available. A comparison of exposure assessments found that the exposure assessment category for the two jobs was identical for 956 of the 978 workers, indicating that job changes did not usually result in different exposures. The cumulative exposure scores were divided into terciles for analysis. Because only one job was available for most subjects, some exposure misclassification by level and cumulative exposure undoubtedly occurred. This type of misclassification is usually random, which would tend to mute exposure response gradients. Information on type of solvent used by the specific establishments where cohort members were actually employed was not available. Thus it was not possible to identify workers specifically exposed to perchloroethylene; however, separate analyses of workers first employed after 1960 focused on those most likely to have contact with perchloroethylene. 


\section{ANALYTICAL METHODS}

Numbers of deaths by underlying cause among dry cleaners were compared with expected numbers based on death rates from the general United States population. Expected numbers were obtained by applying United States death rates from five year age and calendar year race sex specific categories to person-year accumulations from identical strata in the cohort. Person-year accumulation began on the date of entry to the union, or 1 January 1948 (whichever came later), and ended on the closing date of the study (1 January 1979), if alive; the data last known to be alive, if lost to follow up; or the date of death. 1 January 1948 was selected as the earliest date of entry into the follow up because union records were incomplete before that date. For analyses by number of years of union membership and cumulative level of exposure, person-years were allocated to exposure strata so that an individual's total person-years were not placed in the final membership category. Standardised mortality ratios (SMR) were obtained by dividing the number of observed deaths by the expected number. Statistical significance of SMRs was based on $95 \%$ confidence intervals constructed according to Liddell. ${ }^{17} \mathrm{~A}$ chisquared test was used to evaluate the statistical significance of SMR trends. ${ }^{18}$ Standardised rate ratios (SRR) were calculated to compare death rates of heavily exposed dry cleaners to those less intensely exposed, while simultaneously adjusting for differences for race, sex, age, and calendar time by the direct method using the person-year distribution of the entire cohort as the referent population.

\section{Results}

Of the 11062 workers holding union membership between 1945 and 1978, 5790 were members for one year or more (table 2). The 5272 who were members for less than one year were extremely difficult to trace for vital status and cumulative exposure would have $\tau$ been small. For these reasons, they were not included in the analyses. Of the remaining 5790 workers, 425 were missing information necessary for mortality analyses (race, sex, or date of birth) and were excluded, leaving 5365 subjects available for analysis including 407 white men, 912 black men, 2565 white $\vec{\circ}$

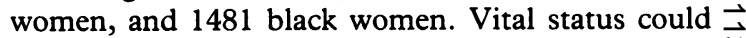
not be determined for $12 \%$ of the cohort (table 3 ). $\stackrel{\omega}{\circ}$ Loss to follow up was similar for white $(12 \%)$ and $\bigcirc$ black $(13 \%)$ workers but lower among men $(9 \%) \frac{\mathbb{D}}{3}$ than among women $(13 \%)$. Table 4 compares subjects included in the analysis with those excluded $\omega$ because of missing information on race, sex, date of $\vec{D}$ birth, or age at entry into the cohort. The latter had, $N$ on average, fewer years of membership (3.5 $v 6.6)$, 옥 had fewer years of follow up $(7.5 v 20.6)$, and had entered the union earlier (1948 $v$ 1956) than subjects 3 included in the analyses. Table 4 indicates that, on average, black men and women were union members slightly longer than white men and women $\left(\begin{array}{llll}7 & v & 6 & \overrightarrow{0}\end{array}\right.$ years) and were younger at entry (early $30 \mathrm{~s} v$ about 8 40). The mean year of birth for black women was 1923 and for the other race/sex groups was before 1920. Mean duration of follow up was about 20 years for each race/sex group.

Table 5 shows mortality for selected causes of death for all race/sex groups combined. Mortality from all causes of death was significantly lower than expected (SMR $=0.9$ ), as was death due to tuberculosis $(S M R=0.5)$. Twice as many deaths from emphysema occurred as expected $(S M R=2 \cdot 0)$. The number of deaths from cancer was greater than expected ( $S M R=1.2)$ with significant excesses occurring for cancers of the oesophagus

Table 2 Number of dry cleaners by race, sex, and study status

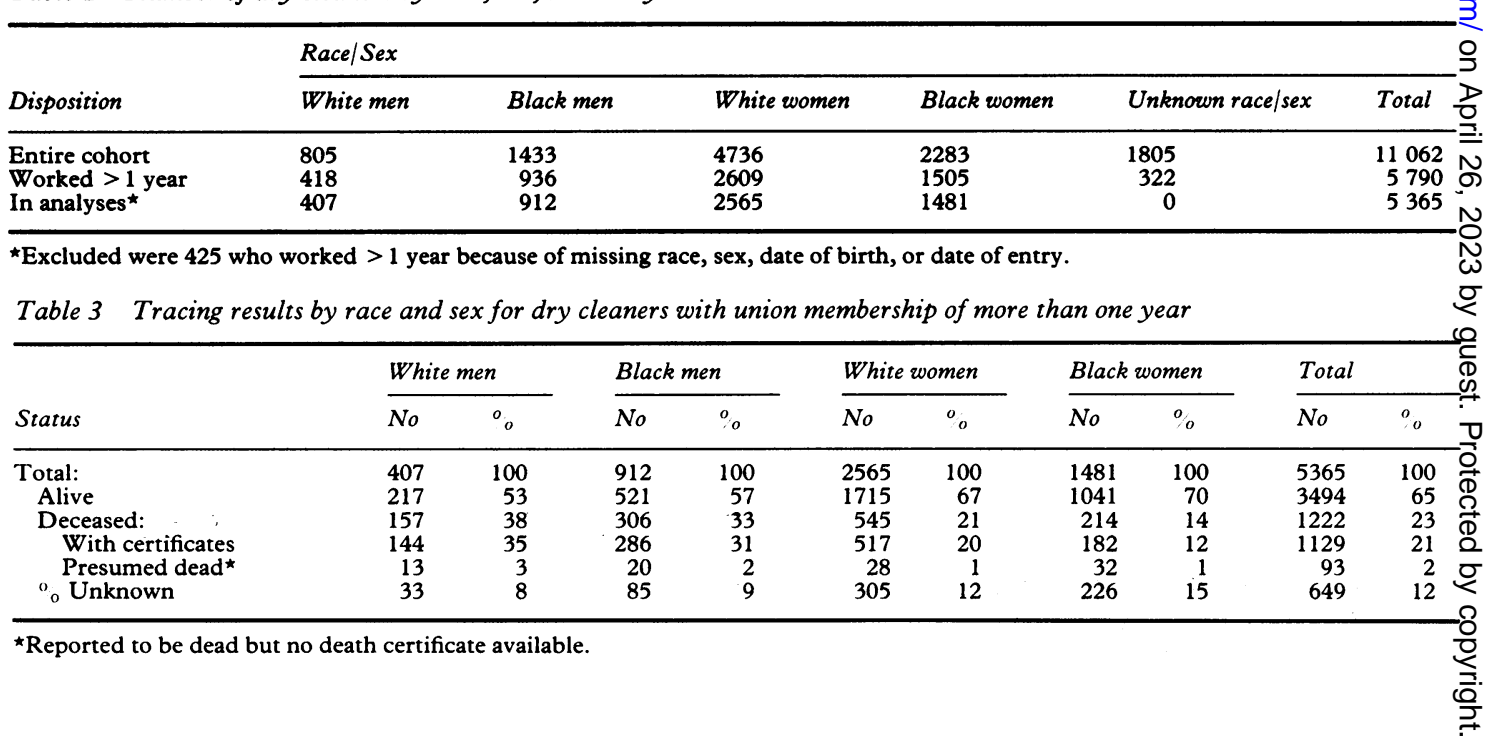


Table 4 Means of selected variables for subjects (included and not included in the analyses) with union membership of more than one year

\begin{tabular}{|c|c|c|c|c|c|c|}
\hline \multirow[b]{2}{*}{ Year } & \multicolumn{5}{|l|}{ Included } & \multirow[b]{2}{*}{ Not included } \\
\hline & White men & Black men & White women & Black women & Total & \\
\hline $\begin{array}{l}\text { Year of birth } \\
\text { Age at entry } \\
\text { Year of entry } \\
\text { Years of membership } \\
\text { Years of follow up }\end{array}$ & $\begin{array}{r}1914 \\
39 \\
1954 \\
6 \cdot 0 \\
20 \cdot 6\end{array}$ & $\begin{array}{r}1919 \\
34 \\
1954 \\
6.9 \\
21.9\end{array}$ & $\begin{array}{r}1916 \\
41 \\
1957 \\
6 \cdot 1 \\
20 \cdot 1\end{array}$ & $\begin{array}{r}1923 \\
32 \\
1956 \\
7 \cdot 3 \\
20 \cdot 7\end{array}$ & $\begin{array}{r}1919 \\
37 \\
1956 \\
6 \cdot 6 \\
20 \cdot 6\end{array}$ & $\begin{array}{l}\text { NA } \\
\text { NA } \\
1948 \\
3 \cdot 5 \\
7 \cdot 5\end{array}$ \\
\hline
\end{tabular}

Table 5 Mortality among 5365 dry cleaners for selected causes of death

\begin{tabular}{|c|c|c|c|}
\hline Cause (ICDA 8th rev) & $S M R^{\dagger}$ & Obs/exp & $95^{\circ} \% \mathrm{CI}$ \\
\hline All causes & $0 \cdot 9^{\star}$ & $1129 / 1207 \cdot 9$ & $0.9-1 \cdot 0$ \\
\hline Infective and parasitic diseases (000-009) & $0 \cdot 6$ & $15 / 23 \cdot 2$ & $0 \cdot 4-1 \cdot 1$ \\
\hline Tuberculosis $(010-019)$ & $0 \cdot 5^{\star}$ & $6 / 13 \cdot 1$ & $0 \cdot 2-1 \cdot 0$ \\
\hline All cancers $(140-209)$ & $1 \cdot 2^{\star}$ & $294 / 254 \cdot 2$ & $1 \cdot 0-1 \cdot 3$ \\
\hline Buccal cavity and pharynx (140-149) & $1 \cdot 0$ & $5 / 5 \cdot 2$ & $0 \cdot 3-2 \cdot 2$ \\
\hline Oesophagus $(150)$ & $2 \cdot 1^{\star}$ & $13 / 6 \cdot 1$ & $1 \cdot 1-3 \cdot 6$ \\
\hline Stomach (151) & 0.8 & $11 / 13.9$ & $0.4-1.4$ \\
\hline Colon $(151)$ & $1 \cdot 0$ & $25 / 25 \cdot 6$ & $0.6-1.4$ \\
\hline Rectum (152) & $1 \cdot 4$ & $10 / 7 \cdot 3$ & $0 \cdot 7-2 \cdot 5$ \\
\hline Liver $(155,156)$ & $0 \cdot 7$ & $5 / 7 \cdot 3$ & $0 \cdot 2-1 \cdot 7$ \\
\hline Pancreas (157) & $1 \cdot 2$ & $15 / 12 \cdot 7$ & $0 \cdot 7-1 \cdot 9$ \\
\hline Larynx (161) & $1 \cdot 6$ & $3 / 1.9$ & $0 \cdot 3-4 \cdot 7$ \\
\hline Lung $(162,163)$ & $1 \cdot 3$ & $47 / 37 \cdot 1$ & $0 \cdot 9-1 \cdot 7$ \\
\hline Skin $(172,173)$ & 0.8 & $2 / 2 \cdot 6$ & $0 \cdot 1-2 \cdot 8$ \\
\hline Breast (174) & $1 \cdot 0$ & $36 / 36 \cdot 3$ & $0 \cdot 7-1 \cdot 4$ \\
\hline Cervix uteri (180) & $1 \cdot 7^{\star}$ & $21 / 12 \cdot 4$ & $1 \cdot 0-2 \cdot 0$ \\
\hline Corpus uteri (181) & $1 \cdot 0$ & $8 / 8 \cdot 0$ & $0 \cdot 4-2 \cdot 0$ \\
\hline Prostate (185) & 0.7 & $5 / 7 \cdot 0$ & $0 \cdot 2-1 \cdot 7$ \\
\hline Bladder (188) & $1 \cdot 7$ & $8 / 4 \cdot 8$ & $0 \cdot 7-3 \cdot 3$ \\
\hline Kidney (189) & 0.5 & $2 / 4 \cdot 0$ & $0 \cdot 1-1 \cdot 8$ \\
\hline Brain $(191,192)$ & $0 \cdot 2$ & $1 / 4 \cdot 6$ & $0 \cdot 0-1 \cdot 2$ \\
\hline Thyroid (193) & $3 \cdot 3$ & $3 / 0.9$ & $0 \cdot 7-9 \cdot 8$ \\
\hline Lymphatic/haematopoietic (200-209) & $1 \cdot 2$ & $24 / 20 \cdot 0$ & $0 \cdot 8-1 \cdot 8$ \\
\hline Lymphosarcoma/reticulosarcoma (200) & $1 \cdot 7$ & $7 / 4 \cdot 2$ & $0 \cdot 7-3 \cdot 4$ \\
\hline Hodgkin's disease (201) & $2 \cdot 1$ & $4 / 1 \cdot 9$ & $0 \cdot 6-5 \cdot 3$ \\
\hline Leukaemia (204-207) & 0.9 & $7 / 7 \cdot 9$ & $0.4-1 \cdot 8$ \\
\hline Other lymphatic $(202,203,208)$ & 0.7 & $4 / 5 \cdot 8$ & $0 \cdot 2-1 \cdot 8$ \\
\hline Arteriosclerotic heart disease $(410-414)$ & $1 \cdot 0$ & $314 / 323 \cdot 8$ & $0 \cdot 9-1 \cdot 1$ \\
\hline Pneumonia (480-486) & $1 \cdot 2$ & $35 / 29 \cdot 8$ & $0.8-1.6$ \\
\hline Emphysema (492) & $2 \cdot 0^{\star}$ & $14 / 7 \cdot 0$ & $1 \cdot 1-3 \cdot 4$ \\
\hline Cirrhosis of liver $(571)$ & $1 \cdot 0$ & $24 / 24 \cdot 2$ & $0.6-1.5$ \\
\hline Chronic nephritis (582) & 0.6 & $6 / 10 \cdot 7$ & $0 \cdot 2-1 \cdot 2$ \\
\hline Senility and ill defined conditions $(780-796)$ & 0.8 & $18 / 21 \cdot 4$ & $0 \cdot \overline{5}-1 \cdot \overline{3}$ \\
\hline Motor vehicle accidents $(810-819)$ & 0.7 & $16 / 21 \cdot 7$ & $0 \cdot 4-1 \cdot 2$ \\
\hline Suicide $(950-959)$ & $1 \cdot 0$ & $10 / 9 \cdot 8$ & $0.5-1.9$ \\
\hline
\end{tabular}

Number of person-years $=98818$.

${ }^{\star} \mathrm{p}<=0.05$.

†Age calendar year/race/sex adjusted SMR.

$($ SMR $=2 \cdot 1)$ and cervix $($ SMR $=1 \cdot 7)$. The excess from oesophageal cancer was due to raised mortality among black men (11 of 13 deaths, SMR $=3 \cdot 5$ ). Non-significant excesses occurred for lymphosarcoma and reticulosarcoma $(S M R=1 \cdot 7)$ and cancers of the bladder, primarily among white men and women $(S M R=1 \cdot 7)$, and lung $(S M R=1 \cdot 3)$. SMRs of greater than 1.5 also occurred for Hodgkin's disease $(S M R=2 \cdot 1)$ and cancers of the larynx $($ SMR $=1.6)$ and thyroid $(S M R=3.3)$ but each was based on fewer than five deaths. Mortality by level of exposure is shown in table 6 for selected causes of death using SMRs and SRRs. Fewer deaths from various causes are listed in table 6 than in table 5 because some subjects lacked job titles and could not be included in exposure level analyses. For SRRs, the lowest exposure category with deaths served as the referent. No association between level of exposure and mortality from all cancer or from cervical cancer was evident. Nine of the ten deaths from cancer of the oesophagus occurred among those who held jobs in the medium exposure category and the tenth was in the highest exposure category. The risk of death from cancer of the bladder $(S M R=2.5$ and $S R R=2 \cdot 1$ based on one death) and the lymphatic and haematopoietic system $(\mathrm{SMR}=\mathbf{4 . 0}$ and SRR = 3.7) was highest in the category with the greatest estimated level of exposure to dry cleaning solvents. The exposure response trend was statistically significant (for all race/sex groups combined) 
Table 6 Observed and expected numbers of deaths and relative risks for selected cancers by level of exposure to dry cleaning solvents

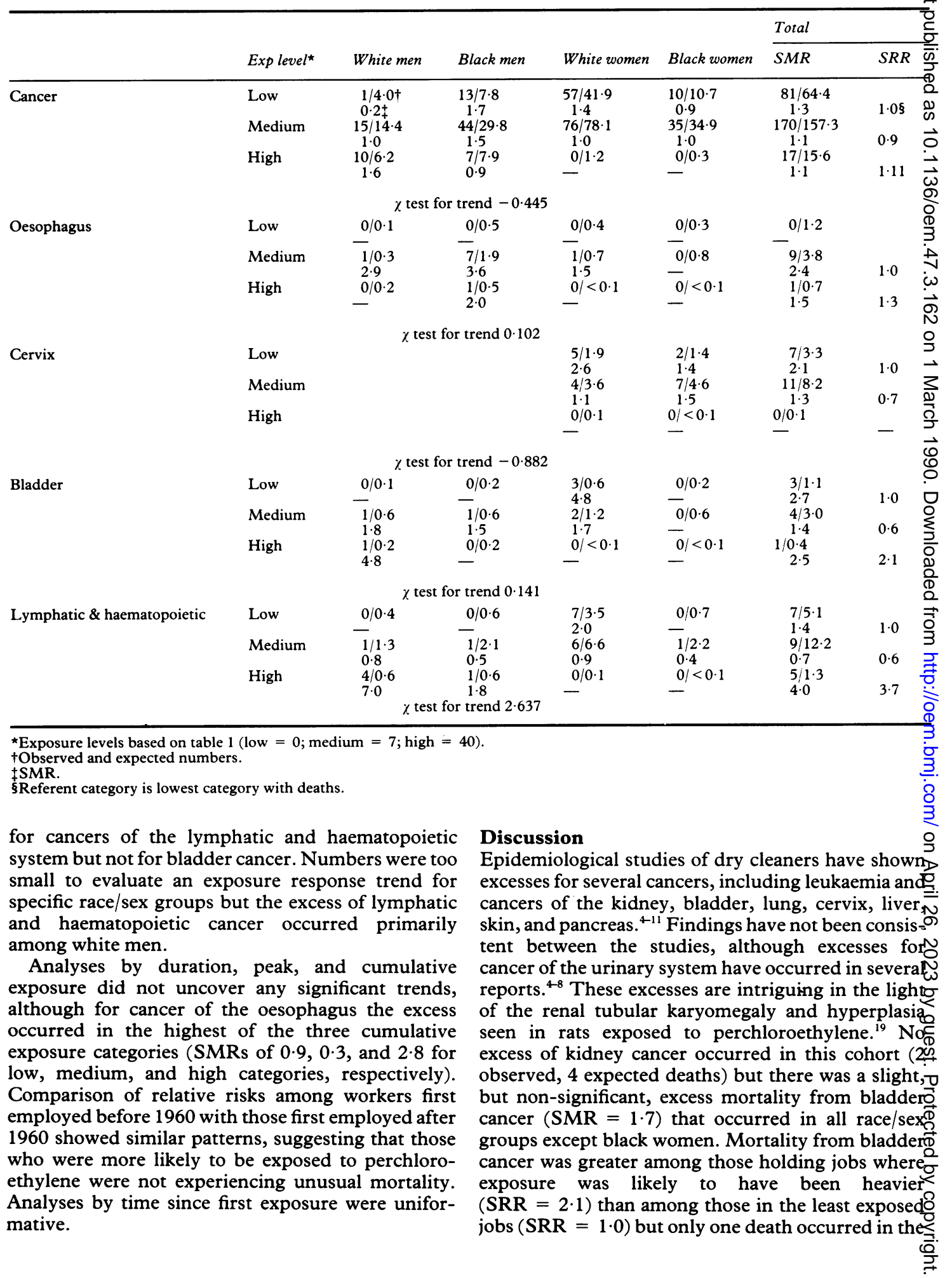


high category. SMRs, however, did not show a positive association with exposure level, which indicates differences in ages between subjects in the various exposure categories. Bladder cancer has been raised in other cohort mortality studies of dry cleaners. ${ }^{58}$ There was no excess for bladder cancer in a case-control study in Iowa ${ }^{20}$ but a significant excess occurred among black men in a study conducted by the (NCI) in the late $1970 \mathrm{~s} .{ }^{20 a}$ In these case-control studies relative risks were adjusted for smoking, something not possible in this, or most other, cohort studies.

The risk of lymphatic and haematopoietic cancer was significantly correlated with level of exposure, rising to about fourfold in the high exposure category $(S M R=4 \cdot 0, S R R=3 \cdot 7)$, although there were only five deaths in this category. Deaths from lymphoma and Hodgkin's disease were raised whereas there was a slight deficit of leukaemia. This contrasts with excesses of leukaemia reported by others, ${ }^{4579}$ which is of interest given the excess of leukaemia occurring among rats exposed to perchloroethylene. ${ }^{19}$

Cancer of the cervix was significantly increased $(\mathrm{SMR}=1.7)$ but the greatest risk occurred among women holding jobs with little or no exposure $(\mathrm{SMR}=2 \cdot 1)$, suggesting that socioeconomic and non-occupational factors ${ }^{21}$ associated with the aetiology of this tumour may be involved. The slight excess of lung cancer did not rise with increasing level of exposure, suggesting that it may be due to tobacco use, since emphysema was also increased. Fewer deaths from liver cancer occurred than expected, in contrast to excesses reported in other epidemiological studies ${ }^{411}$ and among mice exposed to perchloroethylene. ${ }^{19}$

The striking excess of oesophageal cancer among black men (SMR $=3.5)$ was not seen in other race/ sex groups and mortality from this cancer has not been reported as excessive in other studies. Although socioeconomic status, tobacco, and alcohol are strong risk factors for this cancer ${ }^{22}$ and may confound this association, the significantly raised risk in the highest cumulative exposure category $(\mathrm{SMR}=2 \cdot 8$ ) suggests that this site should be looked at in other populations exposed to solvents.

Certain limitations of these data must be considered in interpreting the results. Information on tobacco and alcohol used among members of this cohort was not available. Data from other sources, however, suggest that dry cleaners may smoke more than members of other occupations. ${ }^{23} 24$ Since alcohol use often parallels tobacco use, dry cleaners may also drink more than other occupational groups. No excess was noted, however, for cirrhosis of the liver, often due to excessive consumption of alcohol. Raised mortality from many of the tobacco related causes of death (emphysema and cancers of the oesophagus, larynx, lung, cervix, and bladder) also suggests that socioeconomic status, tobacco, and alcohol use may explain some of the excesses observed. Smoking has not been reported, however, as a strong risk factor for lymphatic and haematopoietic cancer, which was also increased in this cohort. A second limitation is that the significant deficit of deaths from all causes indicates that the "healthy worker effect" was operating ${ }^{25}$ and that relative risks may have been underestimated for specific causes of death. Internal comparisons using direct age/race/sex adjustments (SRRs) partially corrects for this problem by providing a comparison of relative risks of workers more heavily exposed with those with lesser exposure. Unfortunately, small numbers limit the usefulness of this approach. A third limitation is that with the vital status of $12 \%$ of the cohort unknown, some deaths have probably been missed, which may again result in underestimates of relative risks. Fourthly, for some cancers of interest here mortality may not be an accurate reflection of incidence. Cancers of the liver, cervix, and certain leukaemias may be particularly problematical. ${ }^{26}$ Finally, little information was available to estimate exposures. Usually only the job held when first joining the union was available and subsequent job changes were not. Moreover, no information was available on specific chemicals used. Although we developed an index of exposure, it was based on published information not on measurements in plants included in this study. Relative risks for any particular chemical are likely to be diluted by inclusion of unexposed subjects to that chemical in the exposed categories which would tend to reduce estimates of relative risk and to mute exposure response relations.

We thank Violet Herget of Local No 161 of the Laundry, Dry Cleaning, and Dye House Workers' International Union for making records available to assemble this cohort and her help in clarifying information from the records and William Fisher of the International Fabricare Institute for help in coding job titles.

1 National Institute for Occupational Safety and Health. Tetrachloroethylene. (Current intelligence bulletin 20.) Cincinnati: NIOSH, 1978. (DHEW (NIOSH) publ no 78-112.)

2 International Agency for Research on Cancer. Monographs on the evaluation of carcinogenic risks to humans. Overall evaluations of carcinogenicity: an updating of IARC monographs. Vols 1-42. Lyon: IARC, 1987.

3 US Bureau of the Census. County business patterns. Washington; US Government Printing Office, 1975. (US summary CBP75-1.)

4 Blair A, Decoufle P, Grauman DJ. Causes of death among laundry and dry cleaning workers. Am J Public Health 1979;69:508-11.

5 Norman JE, Robinette CD, Fraumeni JF, Jr. The mortality experience of army world war II chemical processing companies. J Occup Med 1981;23:818-22.

6 Duh R, Asal NR. Mortality among laundry and dry cleaning workers in Oklahoma. Am J Public Health 1984;74:1278-80. 
7 Katz RM, Jowett D. Female laundry and dry cleaning workers in Wisconsin: a mortality analysis. Am J Public Health 1981;71:305-7.

8 Brown DP, Kaplan SD. Retrospective cohort mortality study of dry cleaning workers using perchloroethylene. J Occup Med 1987;29:535-41.

9 Lin RS, Kessler II. A multifunctional model for pancreatic cancer in man. JAMA 1981;245:147-52.

10 Stemhagen A, Slade J, Altman R, Bill J. Occupational risk factors and liver cancer. Am J Epidemiol 1983;117:443-54.

11 Hernberg S, Korkala M, Asikaine U, Riala R. Primary liver cancer and exposure to solvents. Int Arch Occup Environ Health 1984;54:147-53.

12 Materna BL. Occupational exposure to perchloroethylene in the dry cleaning industry. Am Ind Hyg Assoc J 1985;46:268-73.

13 National Institute for Occupational Safety and Health. Criteria for a recommended standard ... occupational exposure to tetrachoroethylene (perchloroethylene). Cincinnati: NIOSH 1976. (HEW publ No (NIOSH) 76-185.)

14 National Institute for Occupational Safety and Health. Engineering control technology assessment of the dry cleaning industry. Cincinnati: NIOSH, 1980. (DHHS (NIOSH) vubl No 80-136.)

15 Ludwig HR, Meister MV, Roberts DR, Cox C. Worker exposure to perchloroethylene in the commercial dry cleaning industry. American Industrial Association Journal 1983;44:600-5.

16 Ludwig HR. Occupational exposure to perchloroethylene in the dry cleaning industry. National Institute for Occupational Safety and Health, 1981. (Internal report, DHSS.)

17 Liddell FDK. Simple exact analysis of the standardised mortality ratio. J Epidemiol Community Health 1984;38:85-8.

18 Breslow NE, Lubin JH, Marek P, Langholz B. Multiplicative models and cohort analysis. Journal of the American Statistical Association 1983;78:1-12.
19 National Toxicology Program. Toxicology and carcinogenesis:studies of tetrachloroethylene (perchloroethylene) (CAS No $127-18-4$ ) in $F 344 / N$ rats and $B 6 C 3 F_{1}$ mice (inhalation of studies) (Tech Rep Ser No 311; NIH No 86-2567). Research Triangle Park, US Department of Health and Human Services, 1986.

20 Smith EM, Miller ER, Woolson RF, Brown CK. Bladder cancer $\frac{\bar{\sigma}}{\supset}$ risk among laundry workers, dry cleaners, and others in $\overparen{D}$ chemically-related occupations. J Occup Med 1985;27:295-7. Q

20a Silverman DJ, Levin LI, Hoover RN. Occupational risks of bladder cancer in the United States. II. Nonwhite men. JNCI 1989;81:1480-3.

21 Cramer DW. Uterine cancer. In: Schottenfeld D, Fraumeni JF, eds. Cancer epidemiology and Prevention. WB Saunders, $\vec{\longrightarrow}$ 1982:881-900.

22 Day NE, Munoz N. Esophagus. In: Schottenfeld D, Fraumeni JF, eds. Cancer epidemiology and prevention. WB Saunders, 1982:596-623.

23 Walrath J, Rogot E, Murray J, Blair A. Mortality patterns among " US veterans by occupation and smoking status. Vol 1 . Bethesda: $Ð$ US Department of Health and Human Services, 1985. (NIH i publication No 85-2756.)

24 Sterling TD, Weinkam JJ. Smoking characteristics by type of $\vec{\nabla}$ employment. J Occup Med 1976;18:743-54.

25 McMichael AJ. Standardised mortality ratios and the "healthy 음 worker effect:" scratching beneath the surface. J Occup Med 1976;18:165-8.

26 Percy C, Stanek E, Gloecker L. Accuracy of cancer death $\zeta$ certificates and its effect on cancer mortality statistics. $A m J$ Public Health 1981;71:242-50.

Accepted 10 July 1989

\section{Correspondence and editorials}

The British Journal of Industrial Medicine welcomes correspondence relating to any of the material appearing in the journal. Results from preliminary or small scale studies may also be published in the correspondence column if this seems appropriate. Letters should be not more than 500 words in length and contain a minimum of references. Tables and figures should be kept to an absolute minimum. Letters are accepted on the understanding that they may be subject to editorial revision and shortening.

The journal now also publishes editorials which are normally specially commissioned. The Editor welcomes suggestions regarding suitable topics; those wishing to submit an editorial, however, should do so only after discussion with the Editor. 